\title{
"Fotogramas do Medo" na literatura portuguesa moderna e contemporanea
}

"Frames of Fear" in modern and contemporary portuguese literature

Leonardo de Barros Sasaki

Universidade do Porto

DOI

Resumo: O presente artigo pretende, panoramicamente, destacar nomes basilares da literatura portuguesa moderna e contemporânea pela perspectiva do medo. Em um primeiro momento, apresentam-se as justificativas do foco na emoção, como tema e como elemento inerente da criação. A seguir, discutem-se os limites e dificuldades dessa abordagem. Por fim, a partir de nomes portugueses - mas não só -, desenvolvemos como o medo integra-se às obras ambivalentemente enquanto causa e efeito do ato de escrita. Ao destacarmos o medo, sobretudo na contemporaneidade, acreditamos encontrar uma proteção do trânsito dos afetos e uma resistência à banalização e/ou mecanização da experiência.

Palavras-chave: Literatura portuguesa. Emoções. Medo.

Abstract: This article intends to offer a panoramic view of key names of modern and contemporary Portuguese literature from a fear perspective. At first, we present the reasons for the focus on the emotion as a theme and as an inherent element of literary creation. The limitations and difficulties of such approach are hereafter discussed. Finally, based on Portuguese names - but not only -, we develop how fear ambivalently integrates itself to literary works as a cause and effect of writing. Highlighting fear, especially in contemporaneity, means a protection of the transit of affects and a resistance to impoverishment and / or mechanization of experience.

Keywords: Portuguese Literature. Emotions. Fear. 
Leonardo de Barros Sasaki

Didi-Huberman (2016), ao considerar a ideia de "emoções primitivas" em Darwin, acredita que, para além de sua dimensão estritamente biológica evolutiva, o termo "primitivo" poderia ser entendido, no campo das ciências sociais, pela ideia de história cultural, isto é, de como "elas [as emoções] passam, elas precisam passar, por sinais corporais - gestos - reconhecíveis por todos" (2016, p. 33). As emoções configurar-se-iam, portanto, enquanto textos partilhados e partilháveis, enquanto um código minimamente comum, inserido em determinados contextos históricos e, consequentemente, em constantes mutações. E cita, em seguida, Marcel Mauss, para quem as emoções

são mais do que simples manifestações, são signos de expressões inteligíveis. Numa palavra, são uma linguagem. Esses gritos são como frases e palavras. É preciso pronunciá-los, mas, se é preciso pronunciá-los, é porque todo o grupo pode entendê-los. Mais do que simplesmente manifestar nossos sentimentos, nós os manifestamos para os outros, uma vez que é necessário fazê-lo. Nós os manifestamos para nós mesmos ao exprimi-los para os outros e por conta dos outros. Trata-se essencialmente de uma simbologia (apud DIDI-HUBERMAN, 2016, p. 33).

Sobre a importância da dimensão expressiva e interativa-comunicativa das emoções, o psicólogo Richard J. McNally, ao recolher os diferentes posicionamentos teóricos acerca do medo, sublinha as limitações do modelo não-intencionalista, biologizantes, por ignorar os qualia, isto é, os traços irredutivelmente subjetivos dos estados funcionais que se sucedem no cérebro humano. Ele destaca a "tendência de alguns cientistas em igualar estados cerebrais, detectados por neuroimagens, a emoções em si" (2012, p. 19). Isso ocorreria porque, sobretudo nos modelos animais, desconsidera-se um fator diferencial determinante do medo humano: a autorrepresentação. Através dela, humanos adultos são mais vulneráveis a multiplicar angústias, já que os medos não se atrelam necessariamente ao instante presente e seus, por assim dizer, indícios mais materiais: "a capacidade de autorrepresentação permite que as pessoas projetem-se no futuro e no passado" (McNALLY, 2012, p. 20)ํ․

1 Tradução nossa de "tendency of some scientists to equate brain states, detected via neuroimaging, with emotion itself" e "self-representational capacity enables people to project themselves into the future and into the past". 
Em outras palavras, existe uma dimensão do medo, cuja abordagem não pode prescindir dos qualia; e esses se fazem conhecer de forma privilegiada no campo da linguagem por meio dos autorrelatos - exercícios da dita capacidade humana de autorrepresentação: o relato de si [self-report] é o melhor método, ainda que passível de falhas, para perceber-se o qualia do medo (McNALLY, 2012, p. 19).

Os estudiosos em geral convergem na importância de narrativas de si para o estudo do(s) medo(s). O geógrafo humanista Yi Fu Tuan, por exemplo, fala da dificuldade de recuperarmos relatos escritos por aqueles que os experimentaram, de fato, durante os séculos XVI e XVII, através da fome, da peste e demais calamidades. Para ele, na altura - e ainda não o seria? -, "ser uma vítima era ser desconhecido" (2005, p. 111). A historiadora Joanna Bourke, por sua vez, chama atenção para as disputas quanto

"Fotogramas do Medo" na literatura portuguesa modernae contemporânea à "verdadeira" concepção do medo e às possibilidades de tratamento na primeira metade do século XX. A querela, em muitos aspectos, ignorou os relatos pessoais em suas especificidades: em vez de escutarem-se os pacientes sobre a forma como elaboravam e construíam suas dores e fobias, o medo tornou-se metonímia de contendas acadêmicas por espaços de poder/influência entre diversos campos do saber - a neurologia, psicologia behaviourista e a psicinálise, para citar alguns.

O resguardo que um psicólogo, um geógrafo e uma historiadora fazem em proveito do relato de si - e não o de terceiros - corrobora o incontornável aporte que os estudos literários podem trazer para as abordagens do medo em outras áreas do conhecimento, já que "o próprio ato de narrar altera e formula a 'experiência'” (BOURKE, 2005, p. 288) ${ }^{2}$. Está aí um primeiro lembrete para o trabalho proposto: determinada construção textual - estilística, imagética, narratológica, rítmica etc. - não apenas nos dá a ver as emoções, mas também lhes confere uma forma, uma expressão possível. Em outras palavras, na sequência do que destacou Didi-Huberman (2016), a linguagem desempenha papel importante para o entendimento da experiência emocional, porque, nela, a emoção se exterioriza e, a partir dela, no limite, passa a existir.

Ao apelar às artes - não se restringindo apenas à literatura - como canal de acesso às emoções, os sujeitos ultrapassam as negociações autor/ obra, as quais, em suas consequências últimas, implicariam uma leitura quase terapêutica de sua produção. No caso específico da poesia, por

2 Tradução nossa de "the very act of narrating changes and formulates "experience". 
Leonardo de Barros Sasaki

exemplo, uma lírica com dicção intimista, ancorada na experiência pessoal, ou até mesmo uma opção pela simulação/hibridização dos gêneros autobiográficos, como veremos em alguns casos, vai de encontro a essa lógica ao invertê-la: encontrar no aparentemente mais íntimo, mais narcísico dos gestos, uma abertura - dialogal - para questões supraindividuais, para a partilha dos afetos. Com o declínio das grandes narrativas e das instituições da ordem, o indivíduo e a escrita de si, sua bio-grafia, tornam-se os precários sustentáculos da presença no mundo.

No campo literário, a assimilação do "medo" como constituinte do processo artístico está na gênese da literatura moderna. Walter Benjamin avaliava que a modernidade de Baudelaire assentava-se, dentre outras coisas, no fato de o poeta assumir sua produção enquanto um "duelo em que o artista, antes de ser vencido, dá um grito, assustado". "Esse duelo", continua o crítico, "é o próprio processo de criação. Baudelaire insere assim a experiência do choque no âmago do seu trabalho artístico" $(2015, \mathrm{~s} / \mathrm{p})$.

$\mathrm{O}$ vocabulário assinalado por Benjamin - grito, susto, choque - estará patente em obras das primeiras décadas do século XX português. Em Húmus, obra capital de Raul Brandão, encontramos a seguinte afirmação: "tenho medo de mim, tenho medo da minha alma, tenho medo de me encontrar sós a sós com minha alma, que é nada, o fim e o princípio da vida e a razão do meu ser" (2000, p. 114). 0 medo, aí repetidamente posto, é o choque do homem diante do absurdo, diante da derrocada do sagrado. 0 sujeito que se aplica a buscar o mistério ou que dele se sente órfão só encontra a (anti-)revelação de um vazio que se traduz em camadas de medo: "Atrás deste assombro há outro assombro - e depois outro assombro ainda" (p. 96) ou "Tudo para mim é uma causa de espanto - e através deste espanto pressinto ainda um espanto maior" (p. 103). Como em efeito boneca-russa que terminará no oco de boneca alguma, para quem padece do drama "das consciências", o maior deles "é ficar só com o vácuo e em frente do espanto" (p. 114). A súbita percepção, medonha, do vazio é o que resta para preencher a existência. Tal situação vai minando as certezas mais elementares do indivíduo: "Nem sei o que é a vida. Chamo vida ao espanto" (p. 212). Registremos como esse "espanto", que acaba por ser sinônimo da vida e que estrutura a mundividência brandoniana, compartilha o radical de "pavor" em sua memória etimológica - "expaveo", isto é, "assustar-se, atemorizar-se". 
Mário de Sá-Carneiro, à sua maneira, também construiu uma lírica de repetidos duelos - não com o vazio do sagrado, mas com o do próprio sujeito. Para insistirmos em um substrato lexical comum, sua busca íntima é permeada pelo "pavor" - emoção cuja raiz deu a palavra "medo" em muitas línguas românicas: "Corro em volta de mim sem me encontrar... / Tudo oscila e se abate como espuma... / Um disco de ouro surge a voltear... / Fecho meus olhos com pavor da bruma..." (2010, p. 20). Não surpreende, portanto, que, quando em uma narcísica sala, "deserta e espelhada", ocorra ao eu-lírico a fatídica constatação: "Tenho medo de Mim. Quem sou? Donde cheguei?..." (p. 55).

Álvaro de Campos, por sua vez, é também acossado por um sentimento desestabilizador e ameaçante, sem contornos claros: a "súbita angústia" de "Bicarbonato de soda" (PESSOA, 1998, p. 380). A

"Fotogramas do Medo" na literatura portuguesa modernae contemporânea emoção será repetida em tantos outros poemas: "minha angústia sem leme" (p. 360), "angústia excessiva do espírito por coisa nenhuma" (p. 372) e "Esta velha angústia, / Esta angústia que trago há séculos em mim," (p. 390). o heterônimo pessoano talvez utilizasse com maior acuidade a distinção, já em Kierkgaard e posteriormente em Freud, através da qual a angústia seria um medo sem objeto, sem foco preciso - pois é disso que se trata a dita emoção "sem leme", "por coisa nenhuma". No conjunto da obra pessoana, contudo, tal diferenciação já não se aplica de forma tão evidente no drama $O$ Marinheiro, no qual o(s) objeto(s) do ali chamado "medo" tem contornos bastante imprecisos. Até mesmo o Campos, em outros poemas, dá-nos exemplo de como as nomenclaturas são insuficientes e opta pela acumulação: "relembro, e uma angústia / Espalha-se por mim todo como um frio do corpo ou um medo" (p. 370). Isso também se repete no poema de incipit [O tumulto concentrado da minha imaginação intelectual]:

\footnotetext{
Minha inteligência tornou-se um coração cheio de pavor, E é com minhas ideias que tremo, com a minha consciência de mim, Com a substância essencial do meu ser abstracto Que sufoco de incompreensível, Que me esmago de ultratranscendente, E deste medo, desta angústia, deste perigo do ultra-ser, Não se pode fugir, não se pode fugir, não se pode fugir! (PESSOA, 1998, p. 403, grifos nossos).
} 
Leonardo de Barros Sasaki

Se "pavor", "medo" e "angústia" sinalizam estados mentais de ameaça inescapável - "não se pode fugir", repete-se - que se sobrepõem, em postura pessoana, à experiência corpórea das emoções - o "ser abstracto" -, as emoções igualmente demonstram como a atividade autorreflexiva é, em si, geradora de inseguranças: o perigo não é exterior ao sujeito, mas o habita no "drama das consciências", como diria Brandão.

Dando um salto de décadas, leitor atento do legado brandoniano, Vergílio Ferreira, em seu Para Sempre, apresenta-nos o protagonista Paulo que, em revisitação da antiga residência e de suas memórias afetivas, "entr[a] medroso, travado de prevenção, na decifração do insondável" (1984, p. 80). O dado que aqui mais diretamente nos interessa é que, em 1979, atendendo ao convite da organização do $1^{\circ}$ Simposium Internacional sobre Ansiedade, Vergílio Ferreira profere a conferência “Ansiedade/ angústia e a cultura moderna", na qual pretendia dar relevo à experiência dessa, por ser autocrítica, em detrimento da superficialidade daquela.

Em sua fala, o autor dizia não interessar ao escritor "transpor subtilmente à 'teoria' o que devia ser uma profunda vivência” (1995, p. 64); a arte seria, assim, o arauto "do sentir que não chegou ainda ao entender" (p. 69). o recado de Vergílio, o crítico, é claro: a "profunda vivência" artística - bem como, de resto, da própria experiência afetiva humana - não se enquadra em esquemas preestabelecidos do sentir. Insubordinados, os textos desafiam as classificações, operam por mesclas complexas e sutis e indeterminam-se na ambivalência. Daí, Vergílio, o romancista, igualmente proceder por aglutinação quando o personagem diz procurar a "palavra redentora" "nas esquinas rápidas da minha desorientação, no medo, na angústia, na aflição exorbitada" (1984, p. 66, grifo nosso).

Nesses rápidos fotogramas da tradição portuguesa, já nos é possível exemplificar o quão complexas são as "esquinas rápidas" das emoções, o que, em certo sentido, inutiliza uma taxonomia rígida: os escritores priorizam etiquetas distintas para, no quadro geral, tratarem de estados bastante próximos; muitas vezes, sequer é preciso migrar de um autor a outro, emoções correlatas convivem em um mesmo texto, em um mesmo verso. Se apelássemos aos dicionários, o quadro não é diferente: temos uma ciranda de definições baseadas, muitas vezes, em sinônimos de difícil particularização. No Houaiss, por exemplo, encontramos: assombro: grande espanto; espanto: medo, susto; susto: medo causado por um fato ameaçador súbito e inesperado; horror: repulsa ge- 
rada pela percepção de algo ameaçador; terror: estado de pavor: pavor: grande susto ou temor; temor: medo, receio; receio: incerteza acompanhada de certo medo; pânico: susto ou medo gerado sem fundamento; angústia: estado de ansiedade, inquietude; ansiedade: aflição, agonia.

"Medo" alberga, deste modo, um guarda-chuva de qualidades/ características inter-relacionadas com diferentes intensidades e não apenas um único estado invariável independentemente dos contextos e estímulos diversos. A propósito, quando questionado se atualmente o medo não seria, ao invés, uma angústia ou uma fobia, o filósofo Paul Virilio destaca, na contemporaneidade, a "polissemia" do medo que abarcaria, por fim, as três noções (2012, p. 42). Seguindo a sugestão de Jerome Kagan, em livro intitulado precisamente What is emotion?, adotemos uma moratoria a palavras isoladas como "medo" e "escrevamos sobre o processo emocional com frases completas em vez de conceitos puros e ambíguos" $\left(2007\right.$, p. 216) ${ }^{3}$. Por conseguinte, para que a sanha conceitual não se torne ela mesma uma angústia em nossas abordagens analíticas das emoções no texto literário, ao utilizarmos a palavra "medo", tomamo-la como ponto de partida - e não o oposto - para aproximarmo-nos do amálgama de emoções contido nas obras.

Se, por um lado, tal constatação - a de que o medo não cabe na etiqueta "medo" - torna mais exigente o desafio de tratá-lo em (uma) poesia - afinal, é tema visto pelos mais diversos prismas, com diferentes níveis de compreensão, com narrativas em disputa -, por outro lado, mostra a pertinência do debate na medida em que a poesia - e a arte, de forma geral -, também ela campo movediço, parece-nos a zona de convergência entre a voz lírica, sua dicção particular, a tradição poética e a história mesma da civilização.

Quer seja, sob a espreita de feras, um modo ancestralíssimo de conseguir uma trégua do medo, quer seja, no teatro, uma forma catártica de purificar as emoções, tais hipóteses, com maior ou menor possibilidade de verificação, interessam-nos não para referendarmos necessariamente qualquer uma delas, mas para pontuarmos a intuição antiga de que as expressões artísticas possuem vínculos quase genéticos com a experiência emocional, independentemente de podermos determinar suas reais causas, aplicações e motivações primigênias.

3 Tradução nossa de "let us agree to a moratorium on the use of single words, such as fear [...] and write about emotional process with full sentences rather than ambiguous naked concepts". 
Os rumos dessa estetização do medo são imprevistos. O Museu de Arte Moderna de Nova York (MoMA), entre 2005 e 2006, abrigou a exposição Safe: design takes on risk. No catálogo, a curadora Paola Antonelli, sobre o que chamou de "aesthetics of safety and surveillance", dizia: "Para cada objeto projetado com segurança em mente, há um medo correspondente. Por outro lado, para quase todo medo, há pelo menos um objeto projetado para dissipar a apreensão. 0 medo é um poderoso motor de invenção" (2005, p. 10) e, mais adiante, acrescentava: "Especialmente no cotidiano, a segurança é uma indústria em expansão constante,

Leonardo de Barros Sasaki porque, como não há fim para o que pode dar errado, também não há fim para as possibilidades criativas e comerciais que o design pode oferecer" (p. 118) ${ }^{4}$. Aquilo que Antonelli enxerga como fonte infinita de criatividade tem por pressuposto a ubiquidade do medo da forma como nossa cultura o entende - inclusive em seu potencial comercial.

A arquitetura, assim como o design, tem assimilado esse movimento com projetos sofisticados - bunkers, condomínios, sistemas de vigilância e toda uma gama de "privatização" ou "interiorização" dos espaços públicos -, cujo panorama das discussões está posto de forma instigante em Architecture of Fear. Nan Ellin, a organizadora do volume, no artigo de abertura, afirma que a arquitetura espelha essa atitude, claustrofóbica, de evasão e proteção que tem caracterizado as nossas respostas mais frequentes ao medo. E conclui: "o ambiente contemporâneo construído contém um espaço público cada vez menos significativo, e o existente é cada vez mais controlado por várias formas de vigilância e cada vez mais investido de um significado privado" $(1997, \text { p. } 36)^{5}$.

Se poucos discordam da força catalizadora criativa do medo, tais abordagens nos mostram que a arte pode tanto associar-se ao ideário da segurança e aperfeiçoá-lo continuamente - no paradigma da evasão e autoproteção - quanto encarar suas motivações profundas, resistir a ele e subvertê-lo. Os escritores e pintores aqui evocados estariam, assim, no último grupo, já que, na experiência crítica das emoções, ao buscar dar-lhes

\footnotetext{
4 Tradução nossa de "For every object designed with safety in mind, there is a corresponding fear. Conversely, for almost every fear, there is at least one object designed to allay the apprehension. Fear is a powerful motor of invention" e "Especially in everyday life, security is an industry in constant expansion, because, since there is no end to what could go wrong, there is also no end to the creative and commercial possibilities design can offer".

5 Tradução nossa de "The contemporary built environment contains increasingly less meaningful public space, and existing public space is increasingly controlled by various forms of surveillance and increasingly invested with private meaning".
} 
expressão, questionam e desestabilizam o imperativo privado, asfixiante, ao qual a vida pública tem sido submetida, garantindo, assim, o fluxo do trânsito emotivo. Em contraposição aos sujeitos ávidos por anestesiarem-se do medo e demais emoções ditas "negativas", a arte torna-se poderoso instrumento tanto de resistência e de partilha dos afetos quanto de afirmação da sondagem íntima, da experiência emocional reflexionante - tão ou mais importante que os imperativos da vigilância externa onipresente e da experiência transformada em acumulação de vivências de forma desenfreada, desesperada, et pour cause, irrefletidas.

A seguir tal raciocínio, as expressões artísticas ganhariam corpo enquanto mergulho nesse abismo do homem. Quando observamos os três nomes do modernismo português supracitados - Mário de Sá-Carneiro, Fernando Pessoa e Raul Brandão -, podemos dimensionar

"Fotogramas do Medo" na literatura portuguesa modernae contemporânea a ênfase na tematização do medo por meio dos dramas do sujeito - a fragmentação/vácuo da identidade, a perda do sagrado etc. - trazidos para o interior da poesia. Em Vergílio Ferreira e na produção mais recente, já não se trata essencialmente de um tema, mas também de um componente intimamente ligado - e até estruturante - do ato criativo. Dito de outra maneira, ao abarcar o medo na dimensão metalinguística, autorreflexiva da escrita, os autores paulatinamente deslocam-se de um sujeito com medo para um escrever com medo.

O caso mais emblemático de pesquisa profunda sobre o medo talvez seja o de Al Berto, poeta que produziu entre a década de 1970 até sua morte em 1997 e que reuniu suas obras completas sob o sintomático e incontornável selo de 0 Medo. Nele, encontramos, por exemplo, o poeta que, sob o efeito de "mais drogas", parece retroceder ao momento genético, no qual o homem experimentou, "aterrorizado", o medo pela primeira vez:

\footnotetext{
ingeria cada vez mais drogas, e a dado momento tive a visão do que deve ter sido o primeiro homem a alinhavar, pela primeira vez, o seu nome. parei aterrorizado. ali estava, enfim, a morte da inocência e a revelação do destino que me propunha cumprir: escrever, escrever sempre. a partir desse momento acumulei infindáveis cadernos escritos: era esta a única maneira de remediar o medo e de não possuir nada, e de ter possuído tudo (2009, p. 367)
} 
Leonardo de Barros Sasaki

O despertar da consciência do "primeiro homem" era acompanhado pelo nascer da escrita - enquanto objetivação mesma da subjetividade - e pelas tentativas de "remediar" o medo daí advindo. Em outra versão dessa entrada, contida em rascunhos de seu espólio, o nexo fica ainda mais evidente: "estava, enfim, a inocência, a minha inocência, e com ela revelava-se também o medo e o destino que me propunha: escrever sempre" (E49, cx. 35). Na aproximação medo-destino, "remediar" é verbo ambíguo: pode significar tanto uma cura quanto um paliativo. $O$ conjunto da obra nos mostra, ao seu turno, que não há soluções definitivas para o medo; existem apenas atenuantes.

Se a escrita da intimidade faz de cada indivíduo o Adão de si, a entrada de 14 de junho de 1982 de seus Diários ilustra o quão central é o papel que a emoção desempenha nesse imaginário: "Dantes, eu podia confundir-me às paisagens; hoje, apenas as percorro. Mal pouso as mãos sobre um rio, e já não reconheço as aves que fulguram no fim da memória. Assustado, continuo a viver" (2012, p. 45). "Confundir-se às paisagens" lembra a situação edênica de comunhão com a natureza. 0 seu rompimento, no mito adâmico, marca a concepção da natureza como figura antagonista, por incontrolável, da vontade humana; marca ainda a fundação da consciência, do "percorrer" da experiência em uma obra que se entende como uma "laboriosa travessia da vida", uma "lentíssima decifração do medo e dos sinais" (2009, p. 505). o fim da inocência marca, por fim, o começo da experiência, isto é, a passagem de um estado de indiferenciação com o ambiente para a vivência das individualidades.

O medo, nessa perspectiva, foi a primeira das emoções, aquela que inaugura no homem seu apego primitivo, sua vinculação umbilical à travessia do viver. Adão, após comer o fruto proibido, conversa com Deus: “'Ouvi teu passo no jardim', respondeu o homem, 'tive medo porque estou nu, e me escondi"” (Gen 3:10). o primeiro homem, "assustado, continuou a viver" - ou melhor seria dizer: "começou a viver"?

Também utilizando o medo como emoção iniciática, no caso da vida adulta, Herberto Helder, voz cimeira da poesia portuguesa, morto em 2015, emparelha em seu Photomaton \& Vox as afirmações: "Comecei a ter medo. [...] Esta é realmente minha embaraçosa chegada à maturidade" (2006, p. 32). Continua o poeta, em outra altura, "o medo que faz respirar e viver até a morte" (p. 34). Se até aqui a emoção é um marcador e uma garantia da vida, na obra, ela assume-se ainda como força-violência motriz da escrita: “Apesar de tudo há ainda as palavras que 
nos metem medo. Delas irrompe a cega proliferação de imagens"; é com ele e através dele que as palavras o interpelam, em letras capitais, na práxis inventiva-criativa: “Tens medo? - pergunta-nos a palavra MEDO. Tens medo? - pergunta-nos o MUNDO, sensível, visível forma dessa palavra. E a nossa homenagem à invenção é uma pura urgência do medo" (p. 55). Não seria esse, então, mais um exemplo do dito deslocamento do medo como emoção-etiqueta em poéticas de expressão afetiva para o medo como palavra-emoção que se materializa na escrita e, a partir dela, no limite, é também "sensível, visível forma" em uma poética - e não apenas nelas - com forças cosmogênicas qual a herbertiana?

Maria Rita Kehl, em seu artigo "Elogio ao medo", lembra o quanto, para a arte, o medo pode ser "estímulo à criatividade". Para ela, é o medo, em seu tensionado relacionamento com o desconhecido, que "ocupa

"Fotogramas do Medo" na literatura portuguesa modernae contemporânea grande parte de nossa capacidade de simbolização na esperança de dominar aquilo que, mais cedo ou mais tarde, nos aniquilará" (2007, p. 90). Na mesma direção, Julia Kristeva enxerga no embate que se dá na linguagem um privilegiado ponto de partida para pensarmos o ofício poético e o ofício do medo. De forma lapidar, registra sua premissa: "O escritor: um fóbico capaz de metaforizar não para morrer de medo, mas para ressuscitar nos signos" (1980, p. 49). Para ela, o medo caracteriza-se pela "linguagem da falta" [langage du manque], isto é, aquela que abarca a incapacidade de lidar diretamente com os objetos fóbicos e, por isso, metaforiza-os, simboliza-os. Aí, perde-se "a garantia com a qual usamos geralmente o uso automático da fala, a garantia de ser nós mesmos" (p. 49)

Desarticular a estabilidade/automatização do sujeito e da escrita e subtrair-lhes a ilusão de um mundo "seguro demais de si mesmo" está na base da bildung de Julio Cortázar, conforme diz em crônica de 1983, publicada na revista mexicana Proceso, na qual tematiza sua "infância medrosa":

\footnotetext{
Se o medo me encheu de infelicidade na infância, em contrapartida multiplicou as possibilidades de minha imaginação e me levou a exorcizá-lo com a palavra; contra meu próprio medo inventei o medo para os outros, se bem que ainda não está bem claro se os outros me agradeceram por isso. Em todo caso, creio que um mundo sem medo seria um mundo seguro demais de si
}

6 Tradução nossa de L'écrivain: un phobique qui réussit à métaphoriser pour ne pas mourir de peur mais pour ressusciter dans le signes" e "l'assurance dans laquelle nous tient d'ordinaire l'usage automatique de la parole, assurance d'être nous-mêmes”. 
mesmo, mecânico demais. Desconfio dos que afirmam que nunca tiveram medo; ou estão mentindo, ou são robôs dissimulados, e nem queiram saber o medo que tenho de robôs (CORTÁZAR, 2010, p. 211).

Há aqui a afirmação que antecipa, em certa medida, as precárias conclusões desse artigo: o medo torna-se uma salvaguarda importante do humano em tempos de mecanização da vida, em tempos de controle e vigilância da experiência. 0 depoimento interessa-nos ainda pela ideia

Leonardo de Barros Sasaki de que o autor, a partir da estetização-exorcização de seu medo, gera outros, isto é, a arte torna-se a elaboração de uma emoção autônoma e, por isso, multidimensional que se transmite ao leitor.

Para o poeta Al Berto - e, antes dele, já indiciado em Sá-Carneiro - "inventar o medo para os outros" significa também criá-lo para si em uma poética de espelhos em constante luta com seu(s) duplo(s). Nisso, atribuem-se, aí, novas conotações ao duelo que Benjamin detectava em Baudelaire -: o eu, aqueloutro ameaçador. Nessa diretação, não são raras as ocorrências em que o sujeito manifesta temor diante de suas imagens: "passei a amedrontar-me quando apercebo o meu reflexo nos espelhos" (2009, p. 368). O "coração onde o corpo segrega a agonia da escrita" (p. 63) mostra-nos o ágon, o combate interno, da poesia que, em si, não encontra meios de se apaziguar: "não encontrará na fala sossego algum / depois do susto das palavras murmuradas" (p. 353). Na luta, diferentemente de Cortázar, portanto, Al Berto não tem na escrita uma forma de esconjurar o "susto", causado, inclusive e sobretudo, pelas palavras.

Aquilo que Kristeva (1980) julga inerente a qualquer escritor - a “operação fóbica” de metaforizar - ganha uma tensão irresoluta em Al Berto. Em certo sentido, a literatura é um ato reativo daquele que "escreve para não lhe deixar invadir o medo" (2012, p. 370), como está igualmente dito em epígrafe retirada dos Cadernos de Malte Laurids Brigge, de Rilke, para a primeira edição de sua recolha poética: "Fiz alguma coisa contra o medo. Fiquei toda a noite sentado a escrever" (2009, p. 661). Em outro sentido, é a própria poesia fonte dele: "sempre tive medo quando começo a escrever" (2009, p. 19) e “(j'ai peur d'écrire)" (2009, p. 95).

Outros poetas contemporâneos também têm estruturado a questão através dos dois polos: o medo surge das palavras, como na pergunta de Manuel António Pina, vencendor do Prêmio Camões de 2011 - "Serei capaz / de não ter medo de nada, / nem de algumas palavras juntas?” 
(2001, p. 107); e também nos leva a elas, como diz Filipe de Castro Mendes - "Quase sempre a angústia / instaura a luz por dentro das palavras / e lhes rouba os sentidos. / Quase sempre é o medo / que nos conduz à poesia" (1991, p. 64). O curioso no caso específico de Al Berto é que ambos os paradigmas estão em repetida e inconciliável interação e atrito em um ciclo que se retroalimenta de modo incessante: o poeta é simultaneamente aquele que teme às palavras e que recorre a elas para confrontar o medo.

o processo criativo, dessa maneira, ganha contornos outros que não os de uma expectativa de controle do medo. 0 pintor expressionista Edvard Munch talvez seja um dos casos mais canônicos. Nos escritos que integram seu espólio, encontramos a revelação: "Vim ao mundo assustado e vivi em medo perpétuo da vida e das pessoas" (apud PRIDEAUX, 2005, p. 18). Como no mito adâmico, o advento da consciência

"Fotogramas do Medo" na literatura portuguesa modernae contemporânea é acompanhado pelo medo - "o medo da vida desencadeou-se em mim desde que o pensar [thought] surgiu em minha mente" (p. 19) ${ }^{7}$ - e, como parte constituinte da identidade mesma do indivíduo, entranha-se de forma irreparável:

Eu não quero livrar-me da doença, por mais antipaticamente que eu a descreva na minha arte... O meu medo da vida é necessário para mim, assim como minha doença. Sem a ansiedade e a doença, sou um navio sem leme. Minha arte baseia-se nas reflexões sobre ser diferente dos outros. Meus sofrimentos são parte de mim e da minha arte. Eles são indistinguíveis de mim, e sua destruição destruirá minha arte. Eu quero manter tais sofrimento (apud PRIDEAUX, 2005, p. 251) ${ }^{8}$.

O mais próximo que disso encontramos na obra albertiana foi tomado de empréstimo d'o Marinheiro pessoano: "sentias uma feroz necessidade de ter medo" (2009, p. 596). Se, por um lado, não encontramos em Al Berto uma defesa proclamada do "ser fóbico" como em Munch, o medo é parte indissociável de sua arte - queira ou não. Em entrevista de

7 Tradução nossa de "I came frightened into the world and lived in perpetual fear of life and of people" e "the fear of life that has raged in me since thought entered my mind".

8 Tradução nossa de "I don't want to get rid of illness, however unsympathetically I may depict it in my art... My fear of life is necessary to me, as is my illness. Without anxiety and illness, I am a ship without rudder. My art is grounded in reflections over being different to others. My sufferings are part of my self and my art. They are indistinguishable from me, and their destruction would destroy my art. I want to keep those sufferings". 
Leonardo de

Barros Sasaki

1987 para o Diário Popular, o poeta atribui ao medo a função de nutrição do processo gestacional artístico, reforçando, de certa forma, a primazia da emoção na gênese da vida afetiva:

O título [da recolha de seu trabalho poético] tem a ver com a palavra medo, que aparece com certa insistência no que escrevo. Acho que tenho imenso medo quando escrevo. É a placenta. Quando se nasce tem-se medo, a escrita tem uma relação com o medo, e medo é uma coisa que toda a gente sentiu pelo menos uma vez na vida.

Tratar a emoção como algo a ser 'exorcizado' pela escrita reduz a potência, a violência da qual a poesia se sustenta; tal dimensão ambivalente do medo parece-nos basilar na compreensão da obra albertiana. Para um "pequeno demiurgo" (2009, p. 244), arquiteto atento às intimidades e emoções, o ofício poético não poderia prescindir do medo, não poderia ainda não lhe dar centralidade, quando é ele que inaugura e alimenta - causa e efeito - o próprio ato da criação, quando é ele que instaura um ponto comum, de ligação e partilha, entre os homens: "toda a gente sentiu".

Assim, quebram-se os limites do individual e a arte deixa de ser expressão de fobias particulares para ganhar outra dimensão. Ao citar a obra de outro expressionista, Otto Dix, Virilio adverte que "o medo produziu uma arte que o excede, desconectada dos impulsos que a criaram; torna-se o medo em si [fear itself], uma angústia autônoma" (2012, p. 57) .

Munch, igualmente atento às interioridades afetivas, explica sua poética nos termos de uma necropsia: “Assim como Leonardo da Vinci estudou a anatomia humana e dissecou cadáveres, eu também tentava dissecar as almas" (apud PRIDEAUX, 2005, p. 49) ${ }^{10}$. O medo é a matéria-prima dessa arte, é aquilo que se encontra nos processos dissecantes. Ainda sobre o pintor sueco, em concurso de cenas biográficas, é curiosa a necessidade de localizar na infância a experiência transformadora e inaugural da emoção: “Os anjos do medo, da dor e da morte estiveram

\footnotetext{
9 Tradução nossa de "fear produced an art that outlasts itself, disconnected from the impulses that created; it becomes a fear itself, an autonomous anxiety".

10 Tradução nossa de "Just as Leonardo da Vinci studied human anatomy and dissected corpses, so I was trying to to dissect souls".
} 
ao meu lado desde o dia em que nasci. Eles seguiam-me enquanto brincava - seguiam-me em todos os lugares" (p. 2). Como se marcado por uma sina ditada por um dos anjos tortos drummondianos, que vivem na sombra, o eu-lírico de Livro dos Regressos, dedicado precisamente ao tema, anuncia nos versos iniciais: "do antigo medo da infância regressas / por onde pedra raízes e bichos se tocam" (2009, p. 549) ou, em livro anterior, "nada me pertence aqui, tenho medo deste mobiliário, destes objectos que evocam uma infância pouco feliz" (2009, p. 226).

Para um exemplo a nós contemporâneo, a artista plástica portuguesa de maior expressão internacional na atualidade, Paula Rego também vai à infância para pontuar suas primeiras experiências com a emoção: "gostava daquele frisson de ter medo ao ver gravuras de Doré" (apud RIBEIRO, 2016, p. 24). Nem sempre desejado e prazeroso, sua mãe

"Fotogramas do Medo" na literatura portuguesa modernae contemporânea dizia que a menina "tinha medo de tudo, até das moscas" (2016a), relatou para Notícias Magazine, em 2016. A condição parece não ter mudado na vida adulta - "[quando criança] tem-se medo de muita coisa, e agora também" (apud RIBEIRO, 2016, p. 103) - a ponto de evitar, como nos versos albertianos, até mesmo visitas à sua antiga casa (p. 64). Ao Telegraph, também em 2016, repetiu, autodepreciativa, que a velhice não significou a superação ou apaziguamento dos medos: "Sou hoje a mesma de antes, que azar. É horrível, ainda tenho medo. É ridículo alguém ser tão velho e tão medroso" (2016b, s/p).

Quando perguntada sobre a relação que sua obra teria com a emoção, Paula Rego responde: "É uma forma de enfrentar as coisas que não gostamos de olhar" (apud RIBEIRO, 2016, p. 24) e, mais recentemente, "quando estou a trabalhar esqueço o medo... ou pinto-o" (2016a). Poderíamos talvez acrescentar, retirando-lhe a construção alternativa, que o esquece justamente porque pinta-o. Isso tem a ver com a conjugação de dois fatores: primeiro, aquilo que a motiva como pintora: “interessa-me pintar aquilo que dói, magoa. Que me magoa a mim. Só isso" (apud RIBEIRO, 2016, p. 61); e, segundo, uma constatação ontológica que vai enfaticamente se repetindo nas entrevistas: "O medo é constante. Vive comigo todos os dias" (p. 103) e "Não gosto de acordar. Tenho medo. A minha vida é medo. Medo, medo" (p. 157).

"Minha vida é medo" encerra uma mundividência tão crua e ao mesmo tempo tão produtiva para nossa análise. Descontados certos distúrbios patológicos, todos sentem algo que se poderia chamar de medo, mas ter a vida pautada por ele ou, ainda, ter nele a sua dominante é algo de nature- 
Leonardo de Barros Sasaki

za diversa. Sob essa perspectiva, que lógica subjaz naqueles que, dominados, escavam seus medos e defrontam-se com eles no campo artístico? No que tais sujeitos diferem-se daqueles que, dominados, preferem evitá-lo, amortecê-lo ou pulverizá-lo em sempre renovados medos que acabam por mascarar angústias mais profundas e mais exigentes em sua elaboração?

Qualquer teorização ou categorização sobre isso ignoraria fatalmente a complexidade de relações intrínsecas ao ato criativo. De toda forma, a partir de nosso pequeno acervo de exemplos, poderíamos grosseiramente estabelecer que, para uns, a arte é uma forma - ou tentativa -, ao experimentá-lo, de "libertar-se" do medo, "exorcizá-lo" ou "esquecê-lo"; para outros, não é algo a ser superado, mas parte essencial - voluntária ou não - do processo, pedra angular de uma estética e de um sujeito marcados por uma ruptura, por um desnível com a voltagem convencional dos afetos, que alça maior carga e maior amplitude. 0 esquema, contudo, só funcionará de modo operativo. Além do fato de sentirem-no em excesso, pode haver linhas de continuidade, nuances e qualquer coisa de misterioso na razão de ser do medo que se figura na/pela arte desses dois grupos: "não sei bem explicar como é que é" (p. 61), concluía Paula Rego.

A poeta russa Ana Akhmátova, em poema dedicado a Ossip Mandelshtán, após retratar festivamente a cidade de Vorônej, onde ele vivia "degredado", conclui a ambientação de forma soturna: "Mas, no quarto do poeta degredado / o Medo e a Musa velam em rodízio, / e uma noite cai / que não traz esperança de alvorada" (apud COELHO, 2008, p. 166). Akhmátova proporciona-nos uma amostra do clima de terror vivido na Rússia stalinista que perseguia - e acabaria por vitimar - o amigo poeta. Para além de sua referência mais imediata, tais versos configurariam ainda uma forma de entendimento - e até um modo - do fazer poético. Uma escrita presidida, em iguais proporções, pela inspiração e pelo medo ecoa pergunta lançada por Ruy Belo, poeta que produziu, nas décadas de 1960-70, um interessante trabalho com emoções ainda por ser analisado a contento; perguntava-se ele: "Que nome dar ao poeta esse ser dos espantos medonhos?" (2014, p. 334). O rótulo "poeta", implicitamente, talvez dê conta apenas dos inspirados pelas musas; logo, ficaria ainda por inventar um novo nome para o agente dessa experiência artística - constitutiva e não apenas circunstancialmente - atrelada aos "espantos medonhos": como chamá-lo?

Nessa direção, Alexandre O'Neill, em seu "Poema pouco original sobre o medo" (1984, p. 144-145), escreveu dos versos mais emblemáticos sobre o tema na tradição portuguesa contemporânea. Como no caso de 
Akhmátova, a ditadura do Estado Novo português e seu forte clima de vigilância, delação e ubíqua suspeição configuram os dados circunstanciais do poema datado de 1951 - o que fica sugerido, por exemplo, nos versos “ouvidos não só nas paredes / [...] / e talvez até (cautela!) / ouvidos nos teus ouvidos", que incutem no homem o seu próprio censor. O poema excederia os seus limites históricos. "O medo vai ter tudo", espécie de estribilho, inverte a lógica agente/paciente da emoção e lança-a para o futuro - como é de sua natureza. Acertadamente, o medo continua a ter a nós nas "ambulâncias / e [n]o luxo blindado / de alguns automóveis" ou nas "seguras casas de penhor / maliciosas casas de passe / conferências várias" e, claro, nos "poemas originais / e poemas como este".

São típicos cenários da emoção; por entre eles, não lhe escapava o fato de o medo continuar a gerar arte. Ainda assim, terminava dizendo que "havemos todos de chegar / quase todos / a ratos // Sim / a ratos". Tal conclusão, talvez, padeça da pouca originalidade denunciada no título, pois trata o afeto através do velho binômio coragem/covardia: os amedrontados equivaleriam a meros roedores.

Os dados mais referências, de contextualização, ainda que estruturantes, interessam-nos - e foi essa a opção para os limites desse artigo como ponto de partida para outros desdobramentos. Sob tal perspectiva, é inegável que o medo possa subtrair a dignidade humana em contextos de opressão extrema. A variedade de experiências e pesquisas afetivas, ao seu turno, talvez nos obrigue a desfazer sua expressão na forma de uma antinomia, pois há coragem em se ter medo. Enquanto emoção fundadora de narrativas genéticas coletivas ou pessoalíssimas, ela está no epicentro inconciliável, no lugar em que O’Neill detectava um beco - “Ah o medo vai ter tudo / tudo / (Penso no que o medo vai ter / e tenho medo / que é justamente / o que o medo quer)" (1984, p. 144-45)-, e até mesmo no exato reconhecimento desse sem-saída, ao convertê-lo em verso, a poesia - e a arte de uma forma geral - admite e acolhe o estatuto íntimo desse nosso inimigo interior e deixa-se inundar por ele. Aí, nesse convívio próximo, busca outras potencialidades - violentas, motoras - em que só parecia haver paralisia e cerceamento, mesmo que, para isso, tenha de construir uma obra sempre em choque, sempre entre o ataque e a fuga, entre escrever o medo e temer a escrita - que é justamente o que o medo quer - e, ainda assim ou exatamente por isso, continuar a escrever no recomeçado risco da/sobre a folha branca. 


\section{REFERÊNCIAS}

AL BERTO. O Medo: trabalho poético 1974-1997. Lisboa: Assírio \& Alvim, 2009.

. Diários. Porto: Assírio \& Alvim, 2012.

ANTONELLI, P. Safe: design takes on risk. New York: Museum of Modern Art, 2005.

Leonardo de

BELO, R. Todos os poemas. Porto: Assírio \& Alvim, 2014.

Barros Sasaki

BENJAMIN, W. Baudelaire e a modernidade. Belo Horizonte: Autêntica, 2015.

BOURKE, J. Fear: a cultural history. Emeryville: Shoemaker \& Hoard, 2005.

BRANDÃO, R. Húmus. Edição crítica Maria João Reynaud. Porto: Campo das Letras, 2000.

COElHO, L. M. Anna, a voz da Rússia: vida e obra de Anna Akhmátova. São Paulo: Algol, 2008.

CORTÁZAR, J. Papéis inesperados. Rio de Janeiro: Civilização Brasileira, 2010.

DIDI-HUBERMAN, G. Que emoção! Que emoção? São Paulo: Editora $34,2016$.

ELLIN, N. Architecture of Fear. New York: Princeton Architectural Press, 1997.

FERREIRA, V. Para Sempre. Lisboa: Bertrand Editora, 1984. . Espaço do invisível IV. Lisboa: Bertrand Editora, 1995.

HELDER, H. Photomaton \& Vox. Lisboa: Assírio \& Alvim, 2006. 
HOUAISS, A. Dicionário Houaiss da Língua Portuguesa. Rio de. Janeiro: Editora Objetiva, 2001.

KAGAN, J. What is emotion?: history, measures, and meanings. New Haven: London: Yale University Press, 2007.

KEHL, M. R. O elogio do medo. In: NOVAES, Adauto (Org.). Ensaios sobre o medo. São Paulo: Edições SESC/Editora SENAC, 2007. p. 89-10.

KRISTEVA, J. Pouvoirs de l'horreur. Paris: Editions du Seuil, 1980.

MENDES, L. F. C. A ilha dos mortos. Lisboa: Quetzal, 1991.

"Fotogramas do Medo" na literatura portuguesa modernae contemporânea

McNALLY, R. J. Fear, anxiety, and their disorders. In: LAZIER, B.; PLAMPER (Eds.). Fear across the disciplines. Pittsburgh: University of Pittsburgh Press, 2012.

O'NEILL, A. Poesias completas (1951-1983). Lisboa: Imprensa Nacional Casa da Moeda, 1984.

PESSOA, F. Obra poética. Rio de Janeiro: Nova Aguilar, 1998.

PINA, M. A. Poesia Reunida. Lisboa: Assírio \& Alvim, 2001.

PRIDEAUX, S. Edvard Munch: behind the Scream. London: New Haven: Yale University Press, 2005.

RIBEIRO, A. M. Paula Rego por Paula Rego. Lisboa: Círculo de Leitores, 2016.

ROBIN, C. Fear: the history of a political idea. Oxford: Oxford University Press, 2004.

SÁ-CARnEIRO, M. de. Verso e Prosa. Lisboa: Assírio \& Alvim, 2010.

SASAKI, L. de B. "o temor perene das mãos": Al Berto e a escritura do medo. 2017. Tese (Doutorado em Letras) - Universidade de São Paulo, São Paulo, 2017. 
- Nas esquinas rápidas da desorientação, no medo, na angústia: ler Para Sempre com Al Berto. In: GOULART, R. M. et al. (Eds.). Vergílio Ferreira em Évora: entre o silêncio e a palavra total. Lisboa: Âncora Editora, 2016.

TUAN, Yi-Fu. Paisagens do medo. São Paulo: Ed. UNESP, 2005.

VIRILIO, P. The administration of fear. Los Angeles: Semiotext(e); MIT Press, 2012.

Leonardo de Barros Sasaki

Recebido em maio de 2018

$48 \quad$ Aceito em julho de 2018 